\title{
Integrating Radio-Over-Fiber Communication System and BOTDR Sensor System
}

\author{
Wai Pang $\mathrm{Ng}^{1, * \mathbb{C}}$, Nageswara Lalam $\left.{ }^{2} \mathbb{(}\right)$, Xuewu Dai ${ }^{1}$, Qiang $\mathrm{Wu}^{1}{ }^{1}$, Yong Qing Fu ${ }^{1} \mathbb{D}$, \\ Peter Harrington ${ }^{1}$, Nathan J. Gomes ${ }^{3}{ }^{-1}$ and Chao $\mathrm{Lu}^{4}$ \\ 1 Department of Mathematics, Physics and Electrical Engineering, Northumbria University, Newcastle upon \\ Tyne NE1 8ST, UK; xuewu.dai@northumbria.ac.uk (X.D.); qiang.wu@northumbria.ac.uk (Q.W.); \\ richard.fu@northumbria.ac.uk (Y.Q.F.); peter.harrington@northumbria.ac.uk (P.H.) \\ 2 National Energy Technology Laboratory (NETL), Pittsburgh, PA 15236, USA; \\ Nageswara.Lalam@netl.doe.gov \\ 3 School of Engineering and Digital Arts, University of Kent, Canterbury CT2 7NZ, UK; N.J.Gomes@kent.ac.uk \\ 4 Department of Electronic and Information Engineering, Hong Kong Polytechnic University, Hong Kong; \\ enluchao@polyu.edu.hk \\ * Correspondence: wai-pang.ng@northumbria.ac.uk
}

Received: 20 March 2020; Accepted: 11 April 2020; Published: 15 April 2020

\begin{abstract}
In this paper, we propose and experimentally demonstrate for the first time, the integration of a radio-over-fiber (RoF) communication system and a Brillouin optical time-domain reflectometry (BOTDR) distributed sensor system using a single optical fiber link. In this proof-of-concept integrated system, the communication system is composed of three modulation formats of quadrature phase-shift keying (QPSK), 16-quadrature amplitude modulation (16-QAM) and 64-QAM, which are modulated onto an orthogonal frequency division multiplexing (OFDM) signal. Whereas, the BOTDR sensor system is used for strain and/or temperature monitoring over the fiber distance with a spatial resolution of $5 \mathrm{~m}$ using a $25 \mathrm{~km}$ single-mode silica fiber. The error vector magnitude (EVM) is analyzed in three modulation formats in the presence of various BOTDR input pump powers. Using QPSK modulation, optimized $18 \mathrm{dBm}$ sensing and $10 \mathrm{dBm}$ data power, the measured EVM values with and without bandpass filter are $3.5 \%$ and $14.5 \%$, respectively. The proposed system demonstrates a low temperature measurement error $\left( \pm 0.49^{\circ} \mathrm{C}\right.$ at the end of $\left.25 \mathrm{~km}\right)$ and acceptable EVM values, which were within the 3GPP requirements. The proposed integrated system can be effectively applied for practical applications, which significantly reduces the fiber infrastructure cost by effective usage of a single optical fiber link.
\end{abstract}

Keywords: radio-over-fiber (RoF); distributed fiber sensor; BOTDR

\section{Introduction}

Recent years have seen mobile communication technology growing rapidly, partly due to the huge demand for high data rate services. Fifth-generation (5G) communication network systems are being developed to achieve high data rates. Fourth-generation (4G) technology, such as long term evolution (LTE) and LTE-Advanced, has introduced a network architecture that includes an enhanced NodeB (eNB) and home eNB (HeNB) for both indoor and outdoor wireless applications, respectively [1,2]. In both $5 \mathrm{G}$ and $4 \mathrm{G}$ communication systems, quadrature amplitude modulation (QAM) technique permits a communication system to meet the data rates to match the $4 \mathrm{G}$ and $5 \mathrm{G}$ requirements $[3,4]$.

On the other hand, structural health monitoring is a key element of safety and management of various infrastructures. Conventional fiber sensors, for instance, fiber Bragg grating (FBG) and long period Grating (LPG) sensors measure only at a specific location of interest. Since around 10 years 
ago, the use of Brillouin based distributed fiber sensor systems for structural health monitoring applications has increased rapidly [5,6], due to their high measurement range up to tens of kilometers. The familiar techniques in time-domain based Brillouin fiber sensors are; Brillouin optical time-domain reflectometry (BOTDR) [7] and Brillouin optical time-domain analysis (BOTDA) [8]. The BOTDR system is implemented using spontaneous Brillouin scattering (SpBS) which requires access to one end of the fiber. The BOTDA system uses stimulated Brillouin scattering (SBS) with counter-propagating continuous probe wave and access to both ends of the fiber is essential. Providing a new fiber infrastructure for a distributed sensing system comes at a huge cost with much complexity, which discourages their widespread use. Therefore, sharing an existing data transmission fiber infrastructure for distributed sensing offers cost-effectiveness and efficiency savings. For example, the railway industry uses a fiber infrastructure installed along the track-side for data transmission. The integration of distributed sensing system with the existing optical cable can be used for real-time condition monitoring of land-slides, track ballast, snowdrifts, flooding and line-side fire detection [9]. The integration of distributed sensing and active data transmission using a single optical fiber is an unexplored area of research.

In this paper, we demonstrate a proof-of-concept of simultaneous integration of fiber communication system and the BOTDR sensor system using a single optical fiber, demonstrating the performance of both systems experimentally. For the fiber communication system, the error vector magnitude (EVM) is analyzed for three different modulation formats of quadrature phase-shift keying (QPSK), 16-QAM and 64-QAM at different data and sensing system powers using a $25 \mathrm{~km}$ single-mode silica fiber. In order to evaluate the BOTDR sensor system performance, the temperature effects have been measured and the temperature errors evaluated. To demonstrate the proof-of-concept, we used a single $25 \mathrm{~km}$ fiber spool in the experiments. However, the sensing range can be further improved by in-line erbium-doped fiber amplifier (EDFA) [10] and Raman amplification [11,12], while choosing the optimized larger wavelength spacing between the data and sensing systems. It is significant to remark on certain previous works, such as Cucka et al. [13], which validated a simulation performance based on VPI photonics for phase-sensitive optical time-domain reflectometry (OTDR) into dense wavelength division multiplexing (DWDM) fiber data transmission. In 2017, Munster et al. [14] demonstrated a phase-OTDR system into a dual-polarization QPSK based data system and investigated the Q-factor performance influenced by the phase-OTDR system power. However, in their work, the sensing performance was not investigated in the presence of active data transmission. Therefore, the implementation and purposes of the system proposed in this paper are significantly different. Essentially, the proposed system is based on BOTDR and QAM over OFDM based communication system (aligns to $4 \mathrm{G}, 5 \mathrm{G}$ and beyond implementation [15]), where its performance is experimentally characterized by the simultaneous temperature and communication system EVM measurements.

\section{Integration of Fiber Communication System and BOTDR Sensor System}

The experimental configuration for the integrating BOTDR sensor system and fiber communication system is shown in Figure 1. The BOTDR sensor system is illustrated in a red dashed box of Figure 1. A distributed feedback (DFB) laser at a $1546.12 \mathrm{~nm}$ wavelength and $100 \mathrm{kHz}$ linewidth is used. Thereafter using a 50/50 coupler, the signal is split into two pathways where the upper path signal is used for the optical pulses and the lower path is uses for the local oscillator (LO). The electrical pulses (generated from the pulse generator) are modulated into optical pulses using a dual-drive Mach-Zehnder modulator (DD-MZM). Using the Erbium-doped fiber amplifier (EDFA), the signal is amplified to an optimized power level. The amplified spontaneous emission (ASE) filter (pass-band: $1550 \pm 5 \mathrm{~nm}$ ) is employed to exclude the ASE noise generated from the EDFA. Using MZM 1, the LO signal is modulated by a $10 \mathrm{GHz}$ frequency, which is upshifted and downshifted by $10 \mathrm{GHz}$ from the pump signal. The polarization noise is the dominant noise source in Brillouin based distributed fiber sensor systems, therefore we used a simple and low-cost passive depolarizer to reduce the polarization noise [16]. The backscattered signal from the coupler is connected to the balanced photodetector 
(PDB470C, $400 \mathrm{MHz}$ bandwidth) and analyzed using an electrical spectrum analyzer (ESA) in zero span mode.

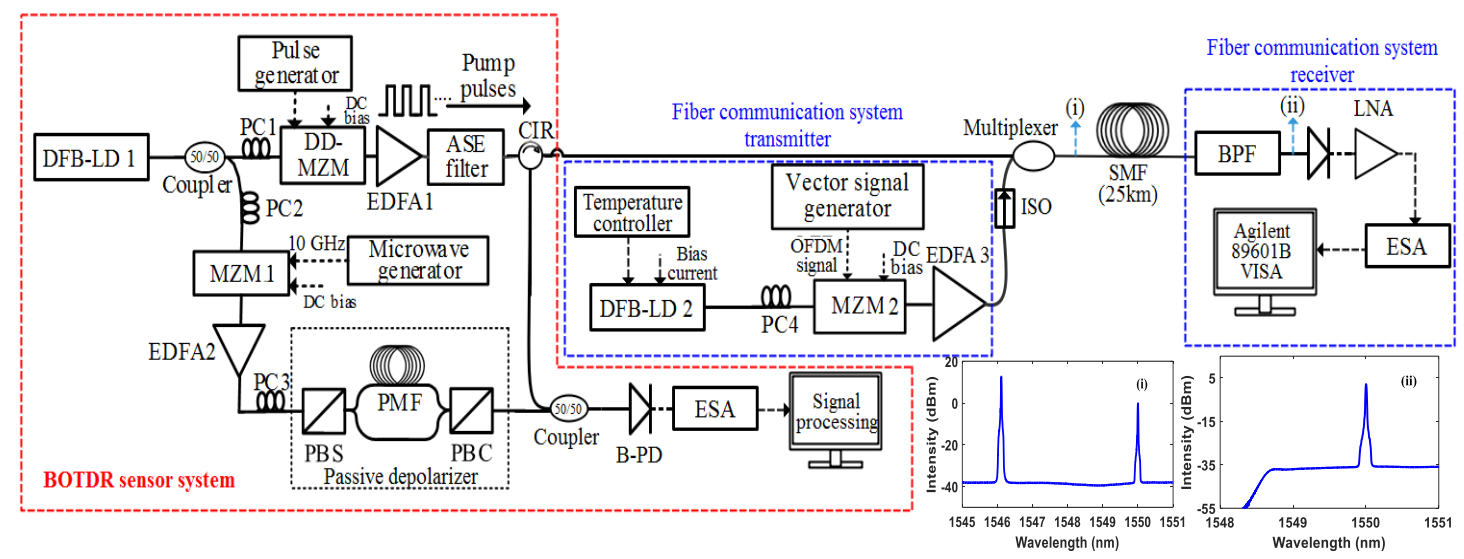

Figure 1. Experimental configuration for the integration of Brillouin optical time-domain reflectometry (BOTDR) sensor system and fiber communication system. (DFB-LD = distributed-feedback laser diode, $\mathrm{PC}=$ polarization controller, $\mathrm{MZM}=$ Mach-Zehnder modulator, DD-MZM = dual drive-MZM, EDFA = erbium-doped fiber amplifier, ASE = amplified spontaneous emission, $\mathrm{PBS}=$ polarization beam splitter, $\mathrm{PMF}=$ polarization maintaining fiber, $\mathrm{PBC}=$ polarization beam combiner, $\mathrm{CIR}=$ circulator, $\mathrm{B}-\mathrm{PD}$ : balanced photodetector, ESA = electrical spectrum analyzer SMF = single-mode fiber, ISO = isolator, $\mathrm{BPF}=$ band pass filter, LNA = low noise amplifier).

The experimental setup of the fiber communication system transmitter and receiver is illustrated in Figure 1 (showed in blue dashed box). A DFB laser diode provides a continuous wave (CW) at $1550 \mathrm{~nm}$ wavelength with a temperature controller, to maintain a constant laser temperature at $25{ }^{\circ} \mathrm{C}$. The laser emission is then externally modulated using an MZM (Photline, MXAN-LN-20). The polarization controller (PC) is used before the MZM to attain maximum power at the MZM output. In this configuration, the data signal is generated by a vector signal generator (Agilent-E4438C) with three modulation formats of QPSK, 16-QAM and 64-QAM with OFDM signal independently. The vector signal generator produces a real-time OFDM signal with a carrier frequency of $2.6 \mathrm{GHz}$ and the channel bandwidth of $10 \mathrm{MHz}$ via Agilent Signal Studio ${ }^{\mathrm{TM}}$ software [17]. After the MZM, the signal is then amplified to the required launch power using an EDFA and then transmitted over a $25 \mathrm{~km}$ single-mode silica fiber link. At the receiver end, the RF signal is detected by a PD (Thorlabs, PDA8GS) and amplified using a low noise RF amplifier (LNA, PE15A1008). Thereafter, the detected signal is analyzed using an electrical spectrum analyzer (Agilent-9020A-MXA), which is automated using Agilent 89601B VSA software. Using the VSA software, the EVM of detected symbols is estimated [18]. The system parameters used in the experiments are defined in Table 1.

Since the BOTDR system requires only single end access of the fiber, the complete BOTDR sensor system is located at one end, as the input pump signal and backscattered signal operate at the same end of the fiber. The pulse width was set to $50 \mathrm{~ns}$, corresponding to $5 \mathrm{~m}$ spatial resolution and the pulse period was $255 \mu \mathrm{s}$. The communication system transmitter was composed of a QPSK, 16-QAM and 64-QAM independently with bit rates of 16, 33 and $50 \mathrm{Mbps}$, respectively. It is significant to employ an isolator after the communication system transmitter; therefore, the signal reflections do not influence the data transmitter operation. The data signal and the sensor signal are simultaneously sent through a multiplexer and then to a $25 \mathrm{~km}$ single-mode silica fiber. At the receiver, a band-pass filter (BPF) is used to eliminate the sensor signal and extract the communication data signal. In the experiment, we employ a $1550 \pm 2 \mathrm{~nm}$ polarization maintaining BPF (AFR's-1550 nm bandpass filter) with a low insertion loss of $1 \mathrm{~dB}$ and maximum optical power handling of $300 \mathrm{~mW}$. Therefore, data detection at the receiver will not be influenced by the sensor system signal. The measured optical spectrums after the multiplexer and BPF are illustrated in Figure 1 inset. 
Table 1. Experimental system parameters.

\begin{tabular}{cccc}
\hline \multicolumn{2}{c}{ Fiber Communication System } & \multicolumn{2}{c}{ BOTDR Sensor System } \\
\hline Parameter & Value & Parameter & Value \\
\hline optical wavelength & $1550 \mathrm{~nm}$ & optical wavelength & $1546.12 \mathrm{~nm}$ \\
optical power & 0 to $10 \mathrm{dBm}$ & input pump power & $14,16 \mathrm{and} 18 \mathrm{dBm}$ \\
modulation scheme & QPSK, 16-QAM and 64-QAM & DD-MZM bandwidth & $12 \mathrm{GHz}$ \\
bit rate (at channel & QPSK $=16 \mathrm{Mbps}$ & & \\
bandwidth: $10 \mathrm{MHz})$ & $16-\mathrm{QAM}=33 \mathrm{Mbps}$ & pulse width, period & $50 \mathrm{~ns}, 255 \mu \mathrm{s}$ \\
baseband multiplexing & $64-\mathrm{QAM}=50 \mathrm{Mbps}$ & & \\
carrier frequency & $\mathrm{OFDM}$ & pulse repetition rate & $4.2 \mathrm{kHz}$ \\
channel bandwidth & $2.6 \mathrm{GHz}$ & pulse amplitude & $4 \mathrm{Vpp}$ \\
RF power & $10 \mathrm{MHz}$ & EDFA 1 gain, noise figure & $30 \mathrm{~dB}, 6 \mathrm{~dB}$ \\
MZM bandwidth & $0 \mathrm{dBm}$ & EDFA 2 gain, noise figure & $28 \mathrm{~dB}, 5.5 \mathrm{~dB}$ \\
EDFA gain, noise Figure & $20 \mathrm{GHz}$ & ASE filter passband & $1545-1555 \mathrm{~nm}$ \\
\hline
\end{tabular}

\section{Results and Discussions}

In order to evaluate the data system performance in the presence of sensing system power, the EVM is analyzed at fixed sensing powers of 14,16 and $18 \mathrm{dBm}$. In our experiments, the EVM values are estimated using Agilent VSA software, which is connected to the electrical spectrum analyzer. Firstly, the EVM performance is analyzed based on QPSK modulation using a bandwidth of $10 \mathrm{MHz}$ at $2.6 \mathrm{GHz}$ carrier frequency. Figure 2 shows the measured EVM values against the different data system powers.

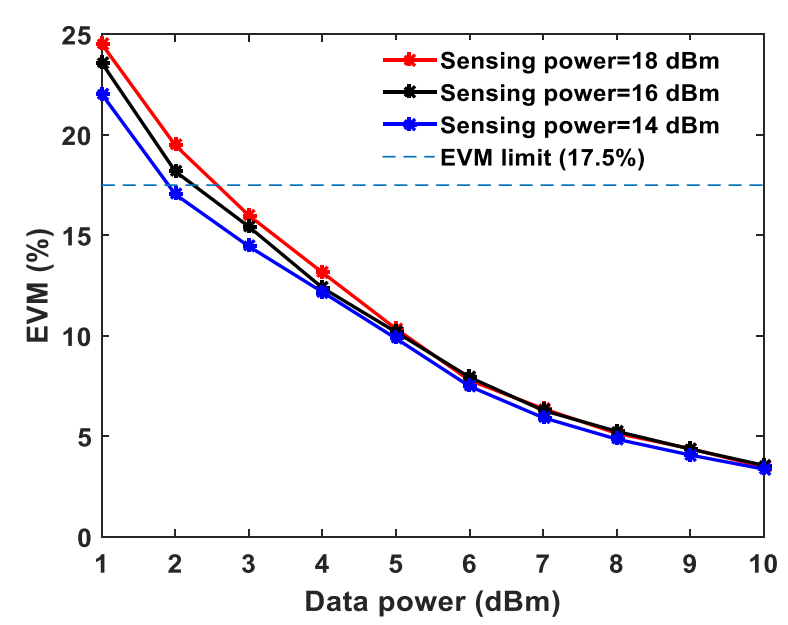

Figure 2. Measured error vector magnitude (EVM) of quadrature phase-shift keying (QPSK) for different data system powers at a fixed sensing power.

The EVM values at $1 \mathrm{dBm}$ data power are $24.5 \%, \sim 23.5 \%$ and $\sim 22.1 \%$ obtained with the sensing powers of $18 \mathrm{dBm}, 16 \mathrm{dBm}$ and $14 \mathrm{dBm}$, respectively. The optimum sensing power is $18 \mathrm{dBm}$ for a $25 \mathrm{~km}$ sensing fiber length [13]. At $10 \mathrm{dBm}$ data system power, the measured EVM values are approximately the same at $\sim 3.5 \%$ for the three different sensing system powers. The interference of the sensor signal and communication signal degrades the communication system performance, therefore, employing a BPF before the photodetector at the communication system receiver end is essential. Unfortunately, due to limited narrow band-pass filter availability, the wavelength spacing has been chosen in the experiments accordingly. The wavelength spacing between the distributed sensor and communication system can be closer to investigate the cross-impact on both the systems. This paper presents a proof-of-concept and feasibility of such emerging systems integration sharing a single fiber cable. In order to demonstrate the need for the optical BPF and mitigate the cross-interference in the proposed system, the EVM is analyzed with and without BPF at a fixed sensing system power 
of $18 \mathrm{dBm}$ with QPSK modulation and the measured EVM values are shown in Figure 3. At $5 \mathrm{dBm}$ data power the measured EVM values with and without BPF are $9.87 \%$ and $37.1 \%$, respectively. Whereas, at $10 \mathrm{dBm}$ data power the measured EVM values with and without BPF are $3.5 \%$ and $14.5 \%$, respectively as shown in Figure 3. Without BPF, the sensing system power significantly influences the data signal, degrading the EVM performance. Thereafter, the EVM values are measured and analyzed for 16-QAM and 64-QAM modulation formats independently at fixed sensing powers, as illustrated in Figure $4 \mathrm{a}, \mathrm{b}$, respectively. In both modulation formats, at a $10 \mathrm{dBm}$ data system power, the EVM values are approximately the same for various sensing powers. The obtained EVM values for 16-QAM and $64-\mathrm{QAM}$ at $10 \mathrm{dBm}$ data system power are $\sim 3.4 \%$ and $\sim 3.6 \%$, respectively. The temperature effects have been measured in both data system and sensing system. The whole $25 \mathrm{~km}$ fiber was kept in a temperature-controlled oven and various temperatures were applied. The data power and sensing system powers are fixed at $10 \mathrm{dBm}$ and $18 \mathrm{dBm}$, respectively. The EVM values of the data system (64-QAM) and Brillouin gain spectrum of the sensing system are measured simultaneously and the results are illustrated in Figure 5a,b. The measured EVM values are fitted with a linear curve and the obtained slope is $0.024 \pm 0.0025 \% /{ }^{\circ} \mathrm{C}$. At room temperature $\left(\sim 25^{\circ} \mathrm{C}\right)$, the obtained BFS is $10.89 \mathrm{GHz}$ and the slope (temperature sensitivity) is $1.07 \pm 0.013 \mathrm{MHz} /{ }^{\circ} \mathrm{C}$.

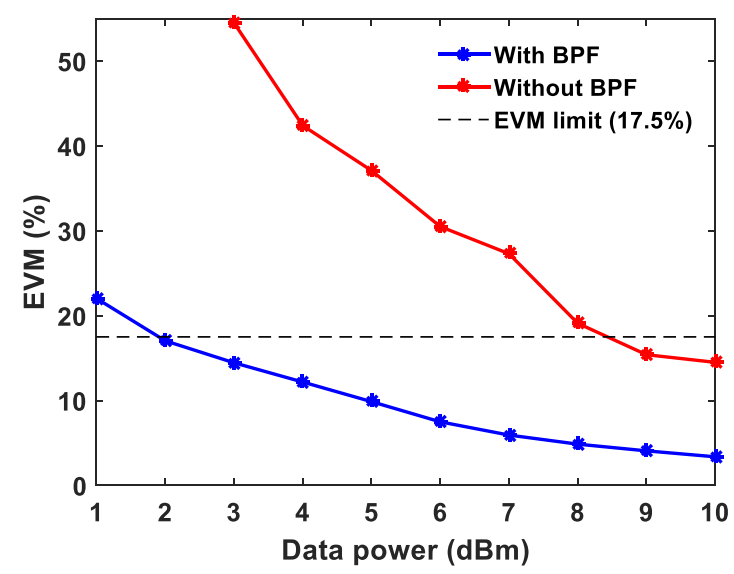

Figure 3. Measured EVM of QPSK modulation with and without band-pass filter (BPF) for various data system powers and fixed sensing power of $18 \mathrm{dBm}$.

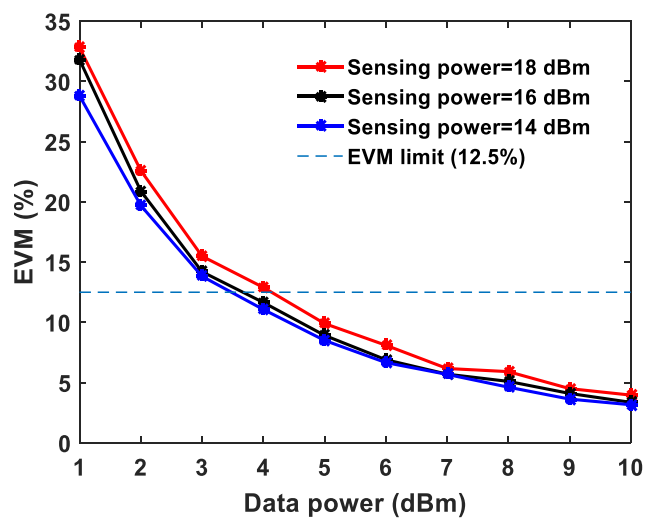

(a)

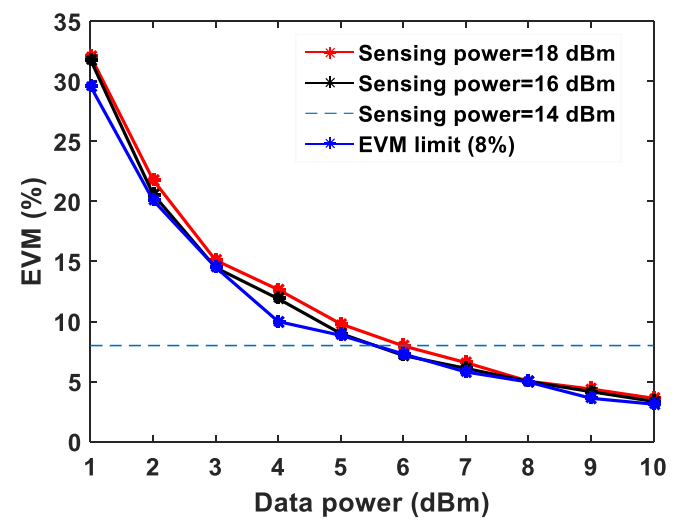

(b)

Figure 4. Measured EVM for various data system powers at a fixed sensing power, (a) 16-QAM (b) 64-QAM with $10 \mathrm{MHz}$ bandwidth. 


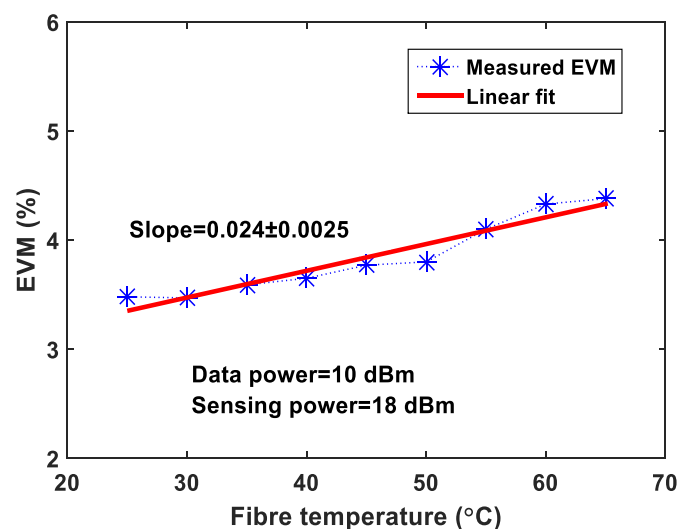

(a)

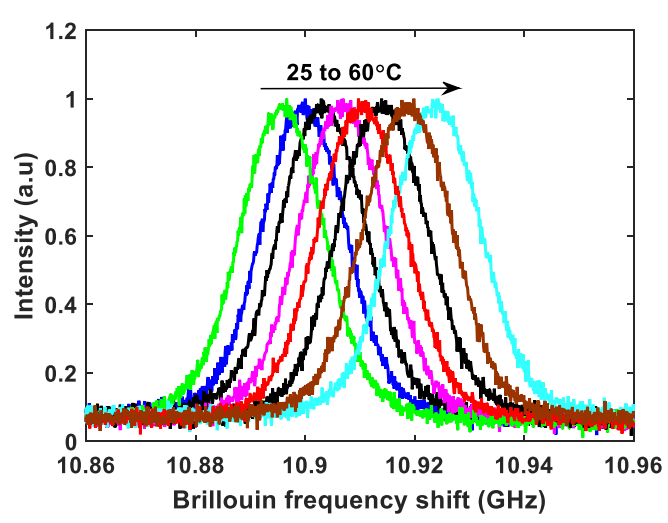

(b)

Figure 5. The temperature effects on (a) data system EVM of 64-QAM (b) sensing system Brillouin gain spectrum (BGS) response.

At room temperature $\left(\sim 25^{\circ} \mathrm{C}\right)$ and at a fixed data system power $(10 \mathrm{dBm})$ and a sensing power $(18 \mathrm{dBm})$, the three-dimensional Brillouin spectrum is obtained and shown in Figure 6. Sweeping the Brillouin frequencies from $10.85 \mathrm{GHz}$ to $10.95 \mathrm{GHz}$ and a frequency step of $1 \mathrm{MHz}$, the three-dimensional spectrum was mapped. Using the Lorentz curve fitting, the peak Brillouin frequency over the $25 \mathrm{~km}$ fiber is illustrated in Figure 6 inset.

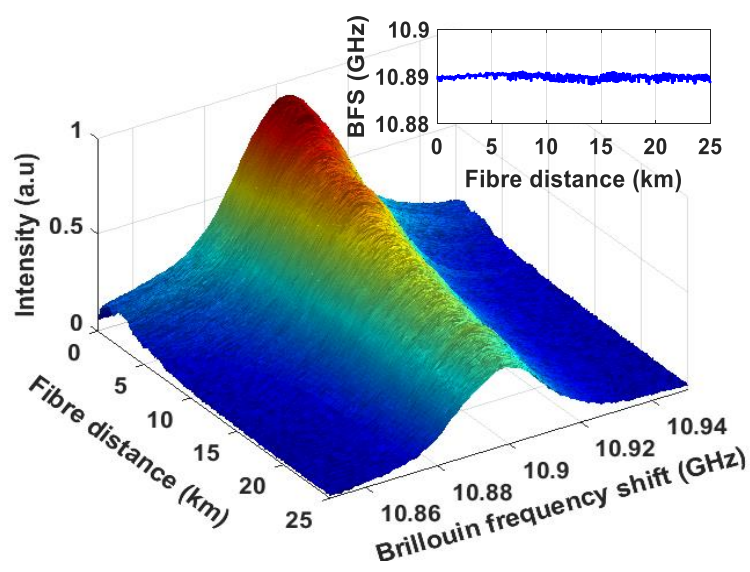

Figure 6. Three-dimensional Brillouin gain spectrum along the $25 \mathrm{~km}$ fiber distance. Inset: BFS distribution along the fiber distance.

Finally, in order to evaluate the sensing system performance and spatial resolution in the presence of active data transmission, a $20 \mathrm{~m}$ fiber length at end of the fiber of the $25 \mathrm{~km}$ fiber is placed in the temperature-controlled oven and the rest of the fiber remains at the room temperature of $25^{\circ} \mathrm{C}$. The temperature was set at $50{ }^{\circ} \mathrm{C}$ in the oven. The peak Brillouin frequency over the $25 \mathrm{~km}$ optical fiber is illustrated in Figure 7 inset. The spatial resolution of $5 \mathrm{~m}$ is attained as shown in Figure 7 , which confirms the $50 \mathrm{~ns}$ pulse width used in the BOTDR sensor system. For a $25{ }^{\circ} \mathrm{C}$ temperature change on $20 \mathrm{~m}$ long fiber at the fiber end, the estimated BFS change is $26.75 \mathrm{MHz}$, as the sensing fiber sensitivity is $1.07 \mathrm{MHz} /{ }^{\circ} \mathrm{C}$. From Figure 7, the measured BFS change is $27.28 \mathrm{MHz}$ for a temperature change of $25^{\circ} \mathrm{C}$. Therefore, the BFS error is $0.53 \mathrm{MHz}$, which corresponds to a temperature error of $\pm 0.49^{\circ} \mathrm{C}$. The results validate a precise temperature measurement without any effects originated from the data communication system. 


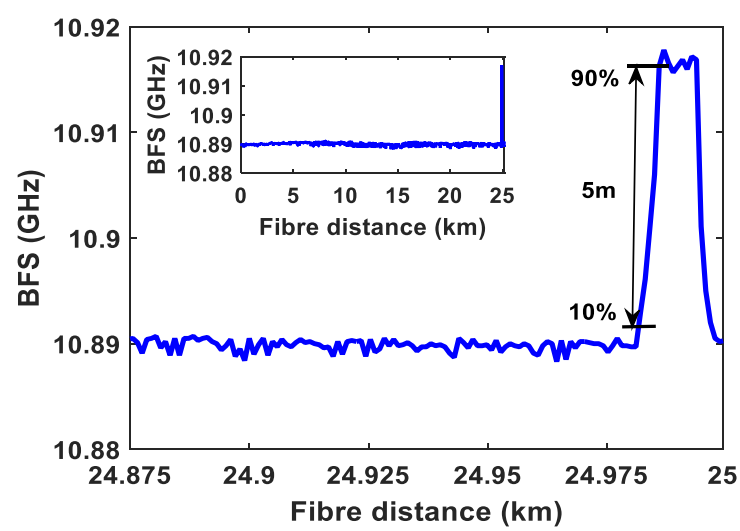

Figure 7. BFS distribution of $50{ }^{\circ} \mathrm{C}$ temperature on $20 \mathrm{~m}$ fiber, (inset: BFS over the whole length of the fibe).

\section{Conclusions}

We have proposed and experimentally demonstrated a proof-of-concept of integrating fiber communication system and BOTDR sensor system using a single $25 \mathrm{~km}$ optical fiber at two different dedicated wavelengths. The communication system EVM performance was investigated using different modulation formats of QPSK, 16-QAM, 64-QAM in the presence of various BOTDR sensor system optimized power levels. The EVM performance with and without BPF before the photodetector of the data system receiver is demonstrated. Using a QPSK modulation and $18 \mathrm{dBm}$ sensing power and at $10 \mathrm{dBm}$ data power the measured EVM values with and without BPF are $3.5 \%$ and $14.5 \%$, respectively. While the BOTDR temperature sensing performance has been investigated in the presence of data system signal. As a result, the measured temperature error is $\pm 0.49{ }^{\circ} \mathrm{C}$ when the applied temperature is $50^{\circ} \mathrm{C}$ at the end of the sensing fiber., Therefore, the proposed system demonstrates a low temperature measurement error $\left( \pm 0.49^{\circ} \mathrm{C}\right)$ and acceptable EVM values, which were within the 3GPP requirements, hence demonstrating the feasibility for practical applications. For further study, the proposed system configuration can be investigated for narrow wavelength spacing between data and sensor system laser wavelengths. The proposed system can be further exploited into DWDM and CWDM based communication system to improve the system performance in terms of larger bandwidth/higher data rate [15]. Furthermore, the BOTDR sensor system can be integrated with other emerging techniques, such as Raman amplification, pump pulse coding and wavelength diversity techniques [19] for further improvement in sensor system performance.

Author Contributions: Conceptualization, W.P.N.; Data curation, Q.W.; Formal analysis, N.L.; Funding acquisition, W.P.N.; Investigation, N.L.; Methodology, N.L.; Supervision, W.P.N. and X.D.; Validation, Q.W., Peter Harrington, N.J.G. and C.L.; Writing - original draft, N.L.; Writing - review \& editing, W.P.N, X.D., Q.W., Y.Q.F., P.H. and N.J.G. All authors have read and agreed to the published version of the manuscript.

Funding: This work is supported by Royal Society Kan Tong Po International Fellowship KTP $\backslash$ R1 $\backslash 181005$.

Conflicts of Interest: The authors declare no conflict of interest

\section{References}

1. Ng, W.P.; Kanesan, T.; Ghassemlooy, Z.; Lu, C. Theoretical and Experimental Optimum System Design for LTE-RoF Over Varying Transmission Span and Identification of System Nonlinear Limit. IEEE Photonics J. 2012, 4, 1560-1571. [CrossRef]

2. Cao, J.; Ma, M.; Li, H.; Zhang, Y.; Luo, Z. A Survey on Security Aspects for LTE and LTE-A Networks. IEEE Commun. Surv. Tutor. 2014, 16, 283-302. [CrossRef]

3. Alhasani, M.M.; Nguyen, Q.N.; Ohta, G.-I.; Sato, T. A Novel Four Single-Sideband M-QAM Modulation Scheme Using a Shadow Equalizer for MIMO System Toward 5G Communications. Sensors 2019, 19, 1944. [CrossRef] [PubMed] 
4. Chávez-Santiago, R.; Szydełko, M.; Kliks, A.; Foukalas, F.; Haddad, Y.; Nolan, K.E.; Kelly, M.Y.; Masonta, M.T.; Balasingham, I. 5G: The Convergence of Wireless Communications. Wirel. Pers. Commun. 2015, 83, 1617-1642. [CrossRef] [PubMed]

5. Barrias, A.; Casas, J.R.; Villalba, S. A Review of Distributed Optical Fiber Sensors for Civil Engineering Applications. Sensors 2016, 16, 748. [CrossRef] [PubMed]

6. Xiaoyi, B.; Lufan, Z.; Qinrong, Y.; Liang, C. Development and applications of the distributed temperature and strain sensors based on Brillouin scattering. In Proceedings of the IEEE ENSORS, Vienna, Austria, 24-27 October 2004; Volume 1213, pp. 1210-1213.

7. Kurashima, T.; Horiguchi, T.; Izumita, H.; Furukawa, S.; Koyamada, Y. Brillouin optical-fiber time domain reflectometry. IEICE Trans. Commun. 1993, E76-B, 382-390.

8. Horiguchi, T.; Kurashima, T.; Tateda, M. A technique to measure distributed strain in optical fibers. Ieee Photonics Technol. Lett. 1990, 2, 352-354. [CrossRef]

9. Minardo, A.; Porcaro, G.; Giannetta, D.; Bernini, R.; Zeni, L. Real-time monitoring of railway traffic using slope-assisted Brillouin distributed sensors. Appl. Opt. 2013, 52, 3770-3776. [CrossRef] [PubMed]

10. Lalam, N.; Ng, W.P.; Dai, X.; Wu, Q.; Fu, Y.Q. Sensing range improvement of Brillouin optical time domain reflectometry (BOTDR) using inline erbium-doped fibre amplifier. In Proceedings of the IEEE Sensors, Glasgow, UK, 29 October-1 November 2017; pp. 1-3.

11. Cho, Y.; Alahbabi, M.; Gunning, M.; Newson, T. 50-km single-ended spontaneous-Brillouin-based distributed-temperature sensor exploiting pulsed Raman amplification. Opt. Lett. 2003, 28, 1651-1653. [CrossRef] [PubMed]

12. Lalam, N.; Lu, P.; Buric, M.; Ohodnicki, P.R. Enhanced performance of Brillouin distributed fiber sensor with hybrid amplification. In Proceedings of the Defense and Commercial Sensing (DCS), Baltimore, MD, USA, 14 May 2019; p. 1100003.

13. Cucka, M.; Munster, P.; Koci, L.; Horvath, T.; Filka, M.; Vojtech, J. Transmission of High Power Sensor System and DWDM Data System in One Optical Fiber. J. Commun. Softw. Syst. 2016, 12, 190-194. [CrossRef]

14. Munster, P.; Radil, J.; Vojtech, J.; Havlis, O.; Horvath, T.; Smotlacha, V.; Skaljo, E. Simultaneous transmission of the high-power phase sensitive OTDR, 100Gbps dual polarisation QPSK, accurate time/frequency, and their mutual interferences. In Proceedings of the Fiber Optic Sensors and Applications XIV, Anaheim, CA, USA, 9-13 April 2017; p. 102080D.

15. Noor, S.; Assimakopoulos, P.; Gomes, N.J. A Flexible Subcarrier Multiplexing System With Analog Transport and Digital Processing for 5G (and Beyond) Fronthaul. J. Lightwave Technol. 2019, 37, 3689-3700. [CrossRef]

16. Lalam, N.; Ng, W.P.; Dai, X.; Wu, Q.; Fu, Y.Q. Performance analysis of Brillouin optical time domain reflectometry (BOTDR) employing wavelength diversity and passive depolarizer techniques. Meas. Sci. Technol. 2018, 29, 025101. [CrossRef]

17. Al-Musawi, H.K.; Cseh, T.; Bohata, J.; Ng, W.P.; Ghassemlooy, Z.; Zvanovec, S.; Udvary, E.; Pesek, P. Adaptation of Mode Filtering Technique in 4G-LTE Hybrid RoMMF-FSO for Last-Mile Access Network. IEEE J. Lightwave Technol. 2017, 35, 3758-3764. [CrossRef]

18. Schmogrow, R.; Nebendahl, B.; Winter, M.; Josten, A.; Hillerkuss, D.; Koenig, S.; Meyer, J.; Dreschmann, M.; Huebner, M.; Koos, C.; et al. Error Vector Magnitude as a Performance Measure for Advanced Modulation Formats. IEEE Photonics Technol. Lett. 2012, 24, 61-63. [CrossRef]

19. Lalam, N.; Ng, W.P.; Dai, X.; Fu, Q.W.Y.Q. Performance Improvement of Brillouin Ring Laser Based BOTDR System Employing a Wavelength Diversity Technique. IEEE J. Lightwave Technol. 2018, 36, 1084-1090. [CrossRef]

(C) 2020 by the authors. Licensee MDPI, Basel, Switzerland. This article is an open access article distributed under the terms and conditions of the Creative Commons Attribution (CC BY) license (http://creativecommons.org/licenses/by/4.0/). 